\title{
Effect of perforated concave delta winglet vortex generators on heat transfer augmentation of fluid flow inside a rectangular channel: An experimental study
}

\author{
Syaiful ${ }^{1, *}$, MSK Tony $\mathrm{SU}^{1}$, Nazaruddin Sinaga ${ }^{1}$, Retno Wulandari ${ }^{2}$ and Myung-whan Bae $^{3}$ \\ ${ }^{1}$ Mechanical Engineering Department, Diponegoro University, 50275 Semarang, Indonesia \\ ${ }^{2}$ Mechanical Engineering Department, Universitas Negeri Malang, 65145 Malang, Indonesia \\ ${ }^{3}$ Mechanical Engineering for Production Department, Gyeongsang National University, 13557 Jinju, \\ Korea
}

\begin{abstract}
Compact heat exchanger with gas as a heat exchange medium is widely used in power plants, automotive, air conditioning, and others. However, the gas has a low thermal conductivity resulting in high thermal resistance causing a low rate of heat transfer. Therefore an improvement to the convection heat transfer coefficient is necessary. One way to enhance the convection heat transfer coefficient is to use a longitudinal vortex generator. However, the increase in convection heat transfer coefficient is followed by an increase in pressure drop. Therefore, this work aims to improve the convection heat transfer coefficient with a low pressure drop. To achieve this goal, experiments were carried out by perforating a longitudinal vortex generator with a diameter of $5 \mathrm{~mm}$ with variations in holes number one, two and three. Two types of longitudinal vortex generators are compared. The experimental results show that the convection heat transfer coefficient for the case of perforated concave delta winglet vortex generator is only decreased by $1 \%$ from that without a hole, while the pressure drop is decreased by $11.6 \%$.
\end{abstract}

\section{Introduction}

The work on the use of vortex generators to increase the heat transfer of heat exchanger has been performed since the $90 \mathrm{~s}$ as proposed by Martin Fiebig in the review paper [1]. In his review paper, a longitudinal vortex generator (LVG) is divided into four types: delta wing, rectangular wing, delta winglet and rectangular winglet. A study into the use of LVG to the increase of heat transfer and turbulent flow numerically has been done by Ting Ma et al. [2]. M. Khoshvaght et al. investigated in detail experimentally the effect of distance among delta winglet vortex generators [3]. They reported that the hydrothermal performance factor is

* Corresponding author: syaiful.undip2011@gmail.com 
slightly increased by using delta winglet VGs. They used delta winglets to generate longitudinal vortices in the flow. Samer Ali et al. used trapezoidal VG to improve heat transfer and fluid mixing [4]. They found that the installation of both flexible and rigid trapezoidal VGs was able to improve the heat transfer by up to $118 \%$ against a non-VG pipe. M. Khoshvaght et al. had previously studied the winglet VGs to enhance heat transfer in tubular heat exchangers [5].

Hao Wu et al. investigated the turbulent flow behind the delta winglet VG [6]. They found the main vortex and induced vortex formed behind the VG. Li Zhang et al. studied the arrangement effects of delta winglet pairs of VGs on the heat transfer enhancement on the shell side [7]. Their work informed that the use of delta winglet VG increases the effectiveness of heat transfer by $16.6 \%$ of that without using VG. The improvement of heat transfer using a longitudinal vortex generator (LVG) has been studied by Gautam Biswas et al. [8]. Zdanski et al. studied the effects of delta winglet VG on convection heat transfer in the arrangement of in-line tubes [9]. They found that the use of delta winglet VGs was able to enhance convection heat transfer by up to $30 \%$, but followed by a $40 \%$ increase in pressure drop. Turo et al. clearly illustrates the effects of different forms of winglet VGs on a fin and tube heat exchanger with herringbone fin form [10]. They found that VGs not only increase heat transfer but also reduce pressure drop. Uddip et al. concentrate to know the effect of the rectangular VG surface-texture on heat transfer and dynamic vortex [11]. They explain that multiple and single texturing on leading and trailing edges can enhance the main vortex behind the VG. Ghobad et al. studied heat transfer improvements inside a diffuser by inserting a delta wing VG [12]. They found an increase in higher heat transfer by using two pairs of delta wing VGs inside the diffuser.

Ralph and Rajnish investigated the VG flag for improved thermal performance [13]. However, their experimental results were lacking to validate numerical and theoretical results. Muhammad Awais and Arafat studied the increase of heat transfer inside a compact heat exchanger by using various forms of vortex generators [14]. They mentioned that the delta winglet VG provides better thermal performance than the rectangular winglet VG. M.J. Li et al. compared the effects of delta winglet VGs on wavy fin and plain fin on thermal performance [15]. They mounted VGs around the tubes. Their experimental results show that using five or six pairs of tubes yields no differences in the rate of heat transfer and pressure drop . Suriya et al. used winglet VGs mounted to the centre of the channel to enhance heat transfer [16]. Their experimental results suggest that the VGs winglet considerably enhances heat transfer and pressure drop over straight pipe, wire coil and twisted tape.

$\mathrm{Hao} \mathrm{Wu}$ et al. observed the longitudinal vortex structure in the downstream of the delta winglet VG on various aspect ratios [17]. They found that the streamwise velocity deficit at the core of the main vortex did not decrease, while the upwash region did not change with increasing aspect ratio. Xuehong $\mathrm{Wu}$ et al. optimized a fin and tube heat exchanger by using genetic algorithms [18]. They tried to learn some geometry parameters of the delta winglet VG by using surface approximation at a certain angle of attack. Zhiming Xu et al. studied the characteristics of heat transfer and fluid flow inside the channel in the presence of VGs [19]. Their results revealed that the half-cylinder VG exhibits the best thermohydraulic performance. Hao Wu et al. studied attack angle effect of the delta winglet VG on the heat transfer enhancement on a flat plate inside a rectangular channel [20]. They found that the average Nusselt number increases with increasing angle of attack. They found that the average Nusselt number increases with increasing angle of attack.

A study into the effects of delta winglet type VG to the increase of heat transfer in a compact plate-fin-and-tube heat exchanger with the actual geometry was conducted by Joardar and Jacobi [21]. From their research showed that air-side heat transfer coefficient increased by $68 \%$ compared with that without using VG. Analysis of the increase in the coefficient of convection in laminar flow using LVG with field synergy principle has been 
introduced by $\mathrm{Wu}$ and Tao [22]. They also studied several variables that affect the increase of heat transfer coefficient. From their analysis, it can be revealed that the increase of heat transfer through VG is due to an increase in the field synergy between the velocity gradient and the temperature gradient. Hung-Yi Li et al. observed experimentally and numerically the thermal-fluid characteristics of the pin-fin heat sink with the delta winglet VG [23]. They found that VG with an attack angle of $30 \square$ provides better thermal-hydraulic performance.

Experimental and numerical studies of 3-D delta wing VG have been given by Aris et al. [24]. The 3D delta wing provides enhancement to heat transfer by $37 \%$ and an increase in pressure loss by $15 \%$. He et al. [25] examined numerically what has been done by Joardar and Jacobi [21] by replacing a delta winglet VG with rectangular winglet. Syaiful et al. has introduced a new type of VG called concave delta winglet (CDW) [26]. They found that the use of CDW VG resulted better in the heat transfer augmentation compared to that of DW VG. However, Syaiful et al. [26] observed that this increase in heat transfer coefficient was accompanied by a higher increase in pressure drop for the CDW VG case. Therefore, current research is focused on reducing pressure drop by applying perforated VGs without reducing the increase in heat transfer coefficient at the certain attack angle.

\section{Material and Experimental Set-up}

\subsection{Experimental set-up}

This experiment was carried out inside a rectangular channel made by a glass with a thickness of $10 \mathrm{~mm}$. This rectangular channel has a length of $370 \mathrm{~cm}$, a width of $8 \mathrm{~cm}$, and a height of $18 \mathrm{~cm}$. The channel was equipped with a hot wire anemometer (Lutron type AM-4204, precision \pm 0.05$) \mathrm{K}$ type thermocouple, acquisition data (Advantech USB 4718 type with precision \pm 0.001 ), a heater, pitot tube, centrifugal fan, straightener, micromanometer (Fluke 922 , accuracy \pm 0.01 ) regulator, camera, laser pointer, transformer, compressor, and wattmeter. Figure 1 shows a schematic diagram of experimental equipment.

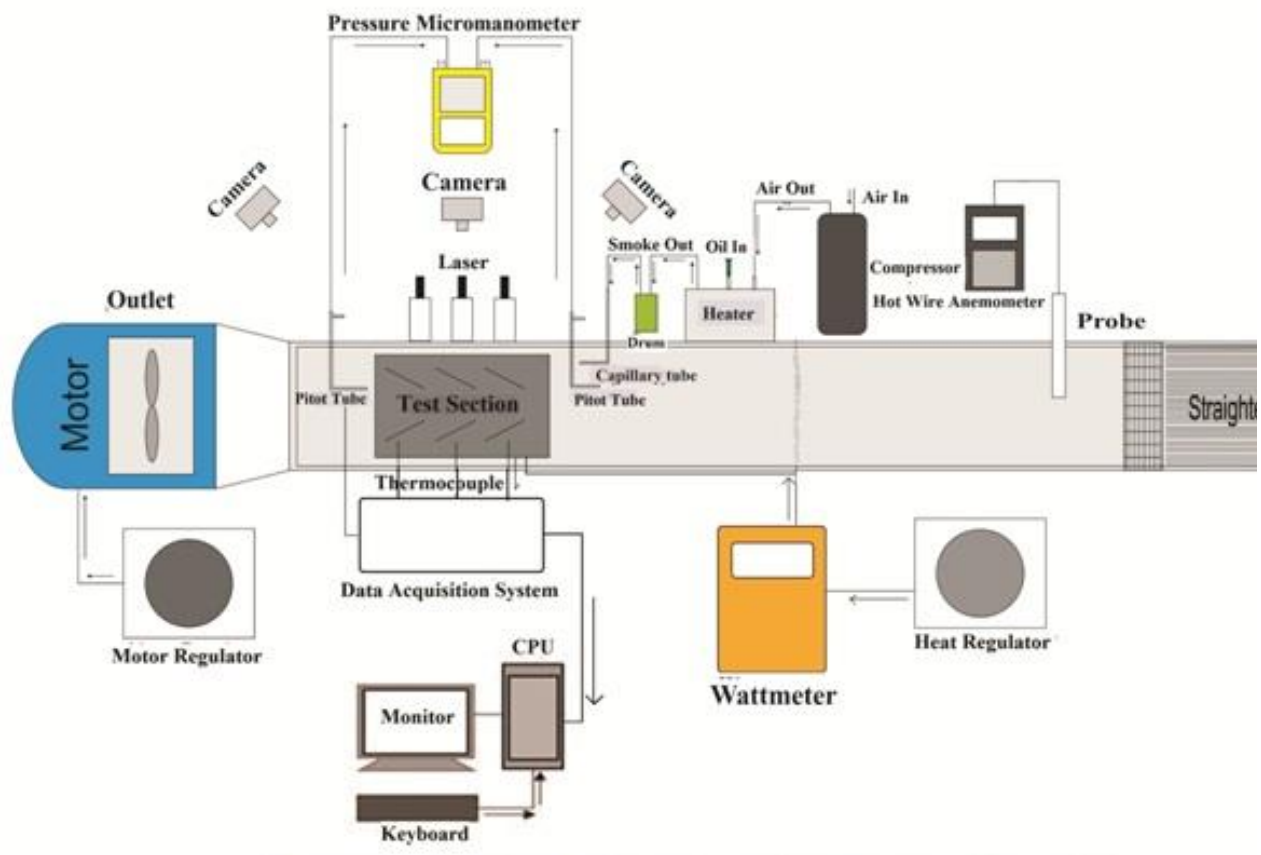

Fig. 1. Schematic diagram of experimental set-up 
A blower was used to suck air into the channel through a straightener that serves to form a uniform flow. A hot wire anemometer was placed at a distance of $27 \mathrm{~cm}$ from the straightener to measure the velocity of air flow within the channel. The inlet air temperature was measured using a thermocouple located above the hot wire anemometer. A regulator was used to regulate the inlet air flow velocity with a blower speed controller. Then, the air flows through the test section consisting of a plate with or without a vortex generator which was heated by a heater. A regulator was connected to a heater to regulate the induced heating power. A $1 \mathrm{~mm}$ thick plate with or without a vortex generator was affixed to the heating plate. Six thermocouples were placed on the surface of the test plate to monitor surface temperatures and six thermocouples were placed behind the test plate to monitor outlet temperatures. The acquisition data were connected to the thermocouple to the PC to record the value of the test plate surface temperature and the outlet temperature. A micromanometer was connected to two hoses on the inlet and outlet sides of the test plate to measure the pressure drop. A heated cylinder tube inside was used to vaporize the oil for flow visualization purposes. A compressor was used to push smoke from the heated oil into the channel.

\subsection{Experimental materials}

This test was performed by installing delta winglet vortex generators (DW VGs) and concave delta winglet vortex generators (CDW VGs) on the test plate. The geometry detail and size of DW VGs and CDW VGs are shown in Figure 2. Figure 3 shows a photograph of a specimen from a plate attached with one, two and three pairs of DW and CDW VGs. Vortex generators were installed on aluminium plate $500 \times 155 \times 1 \mathrm{~mm}$. Vortex generator is in a triangular form with a length of $60 \mathrm{~mm}$ and height of $40 \mathrm{~mm}$. Vortex generators were installed in-line with a distance of $20 \mathrm{~mm}$ and the distance of the forefront of vortex generators with the other pair is $125 \mathrm{~mm}$. DW and CDW VGs was mounted on an attack angle of $15^{\circ}$. In this test, vortex generators have a wide variety of hole numbers. The position of hole 2 is a test specimen for vortex generators with one hole. The positions of holes 2 and 3 are test specimens for vortex generators with 2 holes. The three-hole test specimen uses all holes positions as shown in Figure 2 and Figure 3.

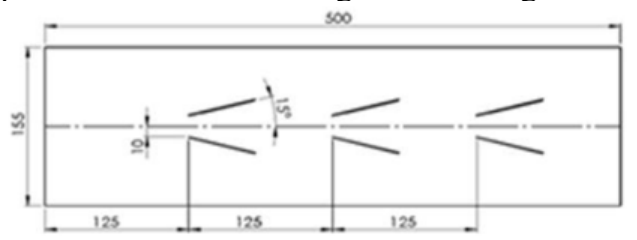

DW VG

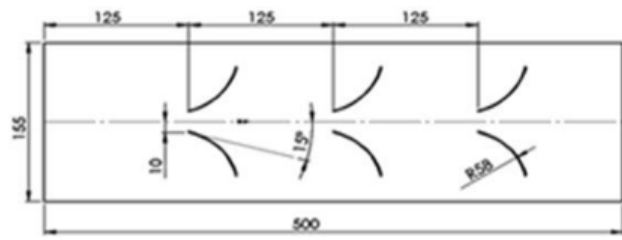

CDW VG

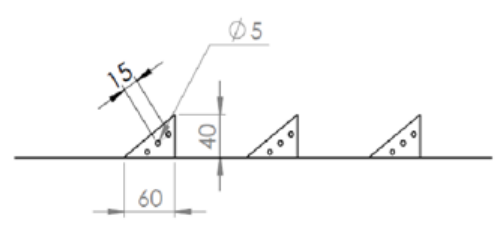

VG size

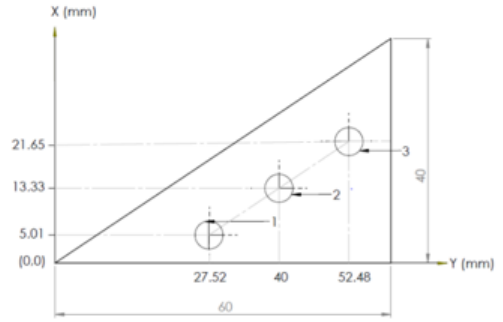

Hole position in VG

Fig. 2. Detail geometry of DW and CDW VGs with hole location 


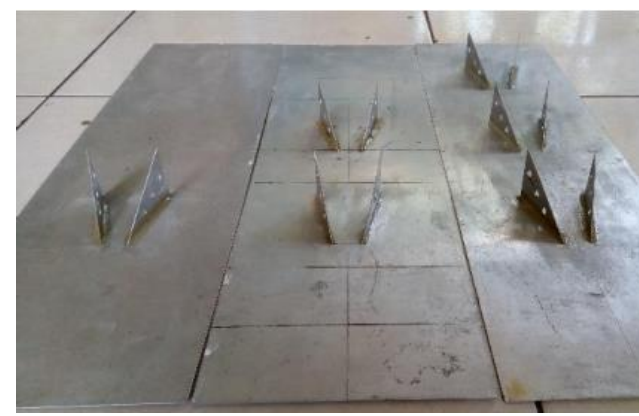

DW VGs

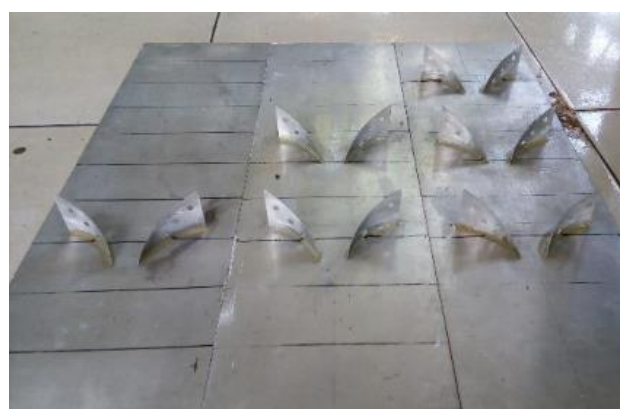

CDW VGs

Fig. 3. A photograph of test specimen for: a. Perforated DW VGs with one, two and three pairs. b. Perforated CDW VGs with one, two and three pairs.

\subsection{Testing procedure}

In this experiment, the value of convection heat transfer coefficient, pressure drop and longitudinal vortex form were determined. Tests for temperature data, pressure drop, and flow visualization were performed separately. Test plates with and without vortex generators was affixed to the heating plate using thermal paste. Then the test plate was heated at a constant heat flux of $35 \mathrm{~W}$ monitored by a wattmeter. A heater regulator was set to achieve the desired heat flux. The heating of the test specimen was carried out until the surface of the test plate reaches a steady temperature of $54-55^{\circ} \mathrm{C}$. After steady temperatures were reached, air was streamed by a blower through a rectangular channel at a velocity variation of $0.4-2.0$ $\mathrm{m} / \mathrm{s}$ with a $0.2 \mathrm{~m} / \mathrm{s}$ interval regulated by the regulator and controlled by frequency control (Freqrol D700 made by Mitsubishi Electric). Surface temperatures of the test plate and inlet and outlet temperatures were measured using several thermocouples connected to data acquisition and recorded within a computer. In pressure drop measurements, two pitot tubes were connected to a micromanometer using two hoses. Each pitot tube was placed on the front and back of the test plate. The data of pressure drop for each variation of flow velocity were recorded by the micromanometer.

In the flow visualization test, two hoses were installed to connect the compressor to a heater and from the heater to the capillary tube. The capillary tube was inserted into the flow field inside the channel in front of the test plate. The blower was turned on to drain air into the channel. For flow visualization, the speed was set at $0.4 \mathrm{~m} / \mathrm{s}$ by adjusting the rotation frequency in the blower using a control frequency. Then the oil was heated in a heating tube and the vapor was suppressed by the compressor through the capillary tube into the flow field. Three laser pen beams were directed into three cylindrical tubes made of transparent material to lend the laser beam to a rectangular channel so that cross sectional areas within the stream are formed in all three places. Vortices can be observed when smoke passes through some cross sections formed from laser beams. These vortices were then recorded by a camera.

\section{Results and discussion}

From several previous literature studies, it can be concluded that the use of VG can increase the rate of heat transfer, but the use of VG impact on the increase of pressure drop. There are several parameters on the use of VG that impact on heat transfer improvements, i.e. VG form, 
placement of VG, angle of attack, VG arrangement and VG number. The use of VG with all of the above mentioned parameters also affects the pressure drop. In the present study is focused on the effect of holes on VGs in lowering pressure drop and its impact on heat transfer rates. In the discussion of the results of this experiment, the effect of variations on the number of VGs rows on the improvement of heat transfer and pressure drop will be discussed. Calculation of convection heat transfer coefficient refers to $\mathrm{Wu}$ and Tao [22].

\subsection{Effect of number of VGs holes on convection heat transfer coefficient}

Figure 4 shows the comparison of convection heat transfer coefficients (h) for the case of delta winglet pairs of vortex generators (DWP VGs) with an attack angle of $15^{\circ}$ without holes and with one, two and three holes. The coefficient of convection heat transfer increases with increasing air velocity. This is due to the stronger and wider swirl flow with increasing air velocity [3]. The highest increase in convection heat transfer coefficient is found at a speed of $2 \mathrm{~m} / \mathrm{s}$ in all cases. At this velocity, the convection heat transfer coefficient in the order of one, two and three lines of DWP VGs is increased by $16.33 \%, 23.67 \%$ and $40.56 \%$ of the baseline cases, respectively. This is due to the increasing number of longitudinal vortex (LV) formed by increasing the VGs row [21]. The generated LV increases the rate of heat transfer by moving the mass of fluid from the hot wall to the main flow [26]. This mass transfer followed by heat transfer accelerates the rate of heat transfer from the hot wall to the fluid.

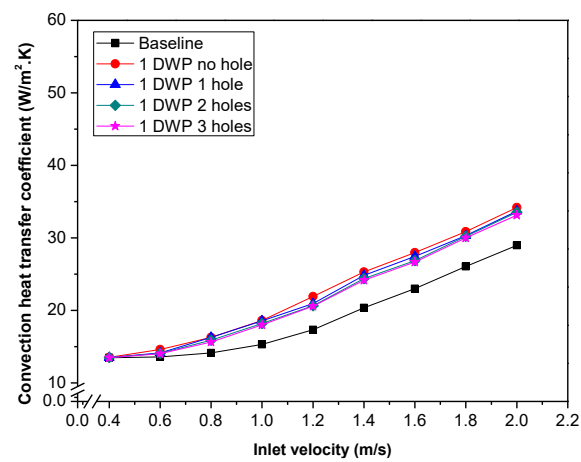

(a)

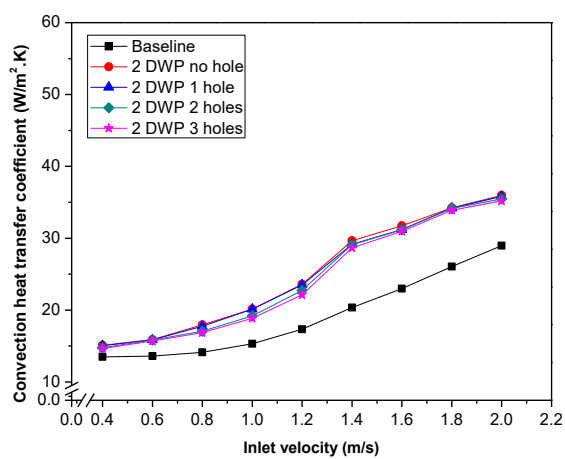

(b)

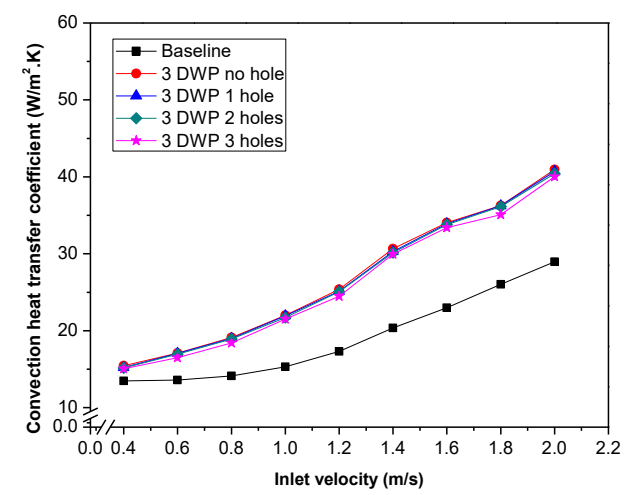

(c)

Fig. 4. Comparison of convection heat transfer coefficient among baseline, DWP VG with and without hole for (a) one DWP VGs, (b) two DWP VGs, (c) three DWP VGs. 
Hole in the vortex generator causes a slight decrease in the convection heat transfer coefficient compared to the vortex generator without holes as shown in Figure 4. The holes in VG result in the flow passing through the hole disturbed thus weakening LV [27]. This resulted in a decrease in convection heat transfer coefficient compared to VG without holes. The convection heat transfer coefficient slightly decreases with increasing number of holes in the VGs. Delta winglet with three holes shows the highest decrease of convection heat transfer coefficient compared to VGs with one and two holes on each number of rows. In Figure 4, DWP three holes with one, two, and three row arrangements shows a decrease in convection heat transfer coefficients of $3.08 \%, 2.14 \%$, and $2.31 \%$, respectively, compared to DWP without holes at the same number of rows.

Figure 5 shows the comparison of convection heat transfer coefficients (h) for the case of the concave delta winglet pair (CDWP) VG of attack angle $15^{\circ}$ with one, two, three holes and without holes. The use of CDWP VGs results in higher convection heat transfer coefficient than DWP VGs type. This is due to the instability of the centrifugal force when the fluid passes through a concave surface that makes the longitudinal vortex stronger [26]. Increased convection heat transfer coefficient of up to $78.89 \%$ of the baseline case is found in the case of three VGs rows with a flow velocity of $2 \mathrm{~m} / \mathrm{s}$. The weakness of LV is found in the case of perforated CDWP VGs due to the disruption of flow through the hole [27]. Similar to those found in the case of DWP VGs, the convection heat transfer coefficient in perforated CDWP VGs cases is observed to decrease slightly at the same flow velocity. By comparing the convection heat transfer coefficients in CDWP VGs cases with and without holes, the convection heat transfer coefficient on perforated CDWP VGs is found to decrease slightly by a maximum of $2.1 \%$. These results indicate that the reduction of convection heat transfer coefficient with the use of perforated CDWP VGs is insignificant.

\subsection{Effect of number of VGs holes on pressure loss penalty}

Figure 6 shows the ratio of pressure drop for the DWP VGs case with an attack angle of $15^{\circ}$ with one, two, three holes with no holes. The use of VG can increase the convection heat transfer coefficient, but also accompanied by an increase in pressure drop [5]. Pressure drop increases with increasing air velocity and number of VGs rows [26]. Increased pressure drop with an increase in air velocity is caused by the addition of drag force [25]. In the case of three rows of DWP VGs three holes with a flow velocity of $2 \mathrm{~m} / \mathrm{s}$, the pressure drop decreases $35.37 \%$ over the three DWP VGs rows without holes. 


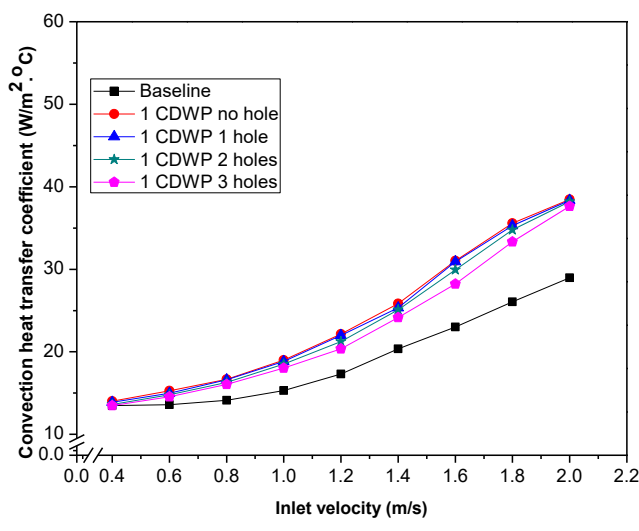

(a)

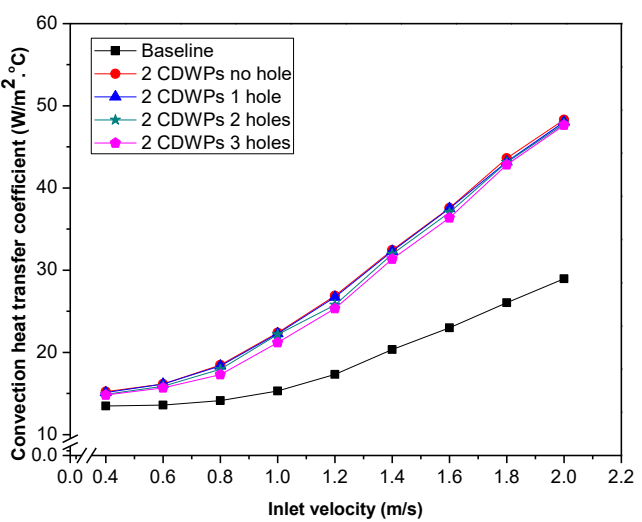

(b)

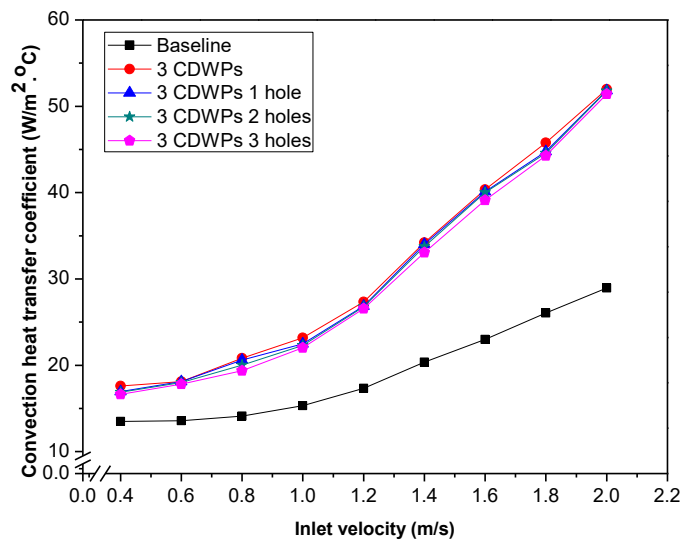

(c)

Fig. 5. Comparison of convection heat transfer coefficient among baseline, CDWP VG with and without hole for (a) one CDWP VGs, (b) two CDWP VGs, (c) three CDWP VGs.

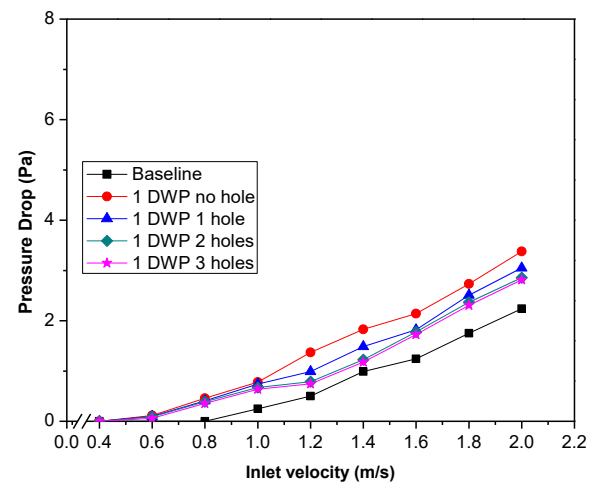

(a)

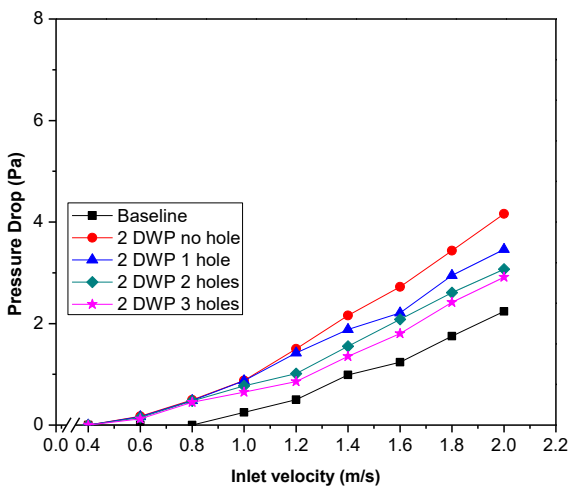

(b) 


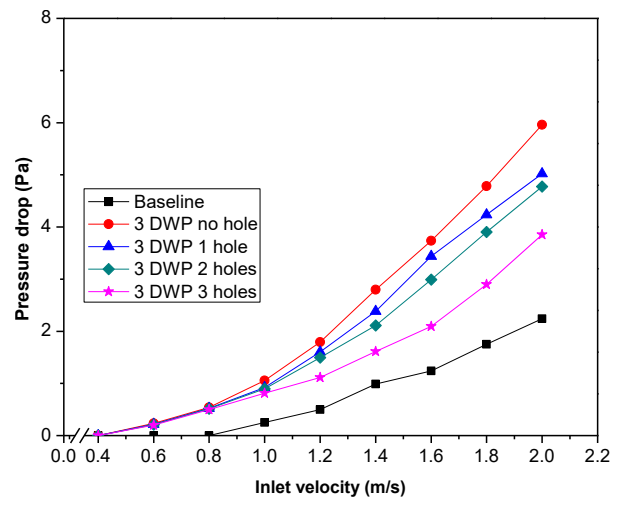

(c)

Fig. 6. Comparison of pressure drop among baseline, DWP VG with and without hole for (a) one DWP VGs, (b) two DWP VGs, (c) three DWP VGs.

Figure 7 shows the ratio of pressure drop for the CDWP VGs case at an angle of attack $15^{\circ}$ with one, two, three holes and without holes. CDWP VGs show a greater pressure drop than DWP VGs because CDWP VGs have a larger surface area than DWP VGs, so the flow resistance becomes larger. Hole in the vortex generator can reduce the flow resistance caused by the longitudinal vortex, so the pressure drop is down compared with VG without holes [27]. Pressure drop decreases with increasing number of holes in VG. Three holes CDWP VGs with one, two, and three row arrangements show a decrease in pressure drop of $25.65 \%$, $13.59 \%$, and $11.62 \%$, respectively, compared to CDWP VGs with no holes on the same number of rows. The largest reduction pressure drop is found on a single row arrangement of CDWP VGs with three holes.

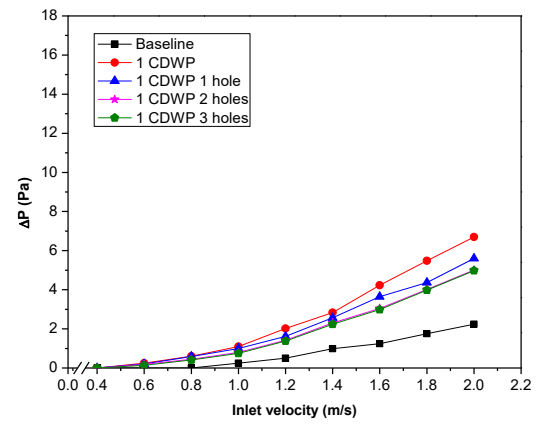

(a)

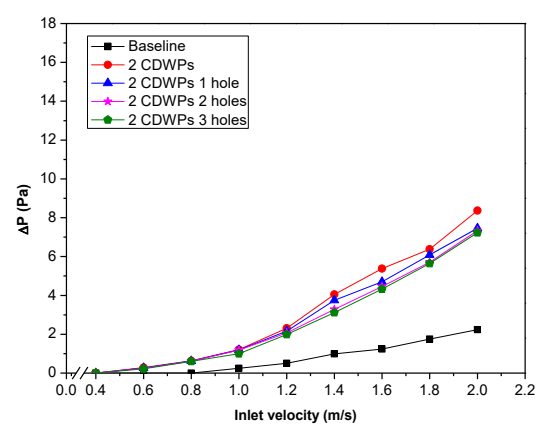

(b) 


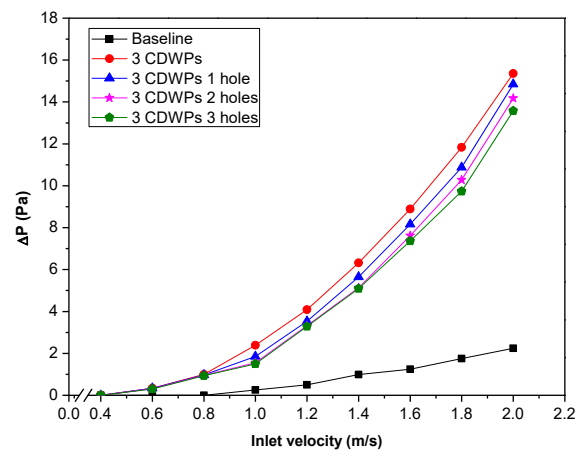

(c)

Fig. 7. Comparison of pressure drop among baseline, CDWP VG with and without hole for (a) one CDWP VGs, (b) two CDWP VGs, (c) three CDWP VGs.

\subsection{Longitudinal vortex visualization}

The visualization of the airflow inside a rectangular channel was carried out within the Thermofluid Laboratory of Diponegoro University with the surrounding environment in a dark condition to see traces of LV in the cross section of laser light. In visualizing this flow, LV was generated by DWP and CDWP VGs with air velocity of $0.4 \mathrm{~m} / \mathrm{s}$ at an attack angle of $15^{\circ}$ as can be seen in Figures 8 . Based on the flow structure, it can be shown that the perforated concave delta winglet vortex generator produces a longitudinal vortex with a larger size area than that of perforated delta winglet vortex generator. The large radius of the longitudinal vortex causes better fluid mixing.

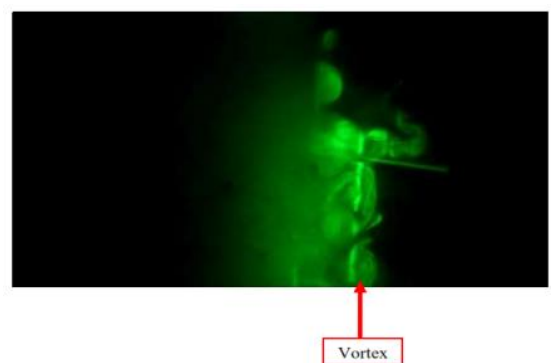

(a)

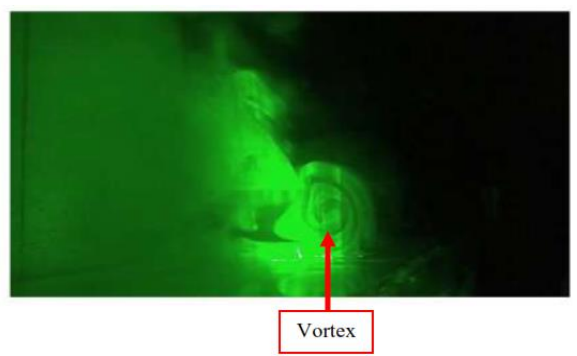

(b)

Fig. 8. Formed longitudinal vortex in the flow for: (a) DWP VGs and (b) CDWP VGs

\section{Conclusion}

Use of a vortex generator can increase the convection heat transfer coefficient and result in increased pressure drop. CDWP VGs increase the convection heat transfer coefficient higher than that of DWP VGs with greater pressure drop. The perforated VG resulted in a slight decrease in the value of convection heat transfer coefficients compared with those without the holes. However, perforated VGs can lower the pressure drop. The flow visualization shows that the LV produced by CDWP VGs is greater than that generated by DWP VGs. 
This work was supported by the Fundamental Research Project of Indonesia (KEMENRISTEK DIKTI). The authors are grateful to all research members, especially Lab. Thermofluid of Mechanical Engineering of Diponegoro University Indonesia, Lab. Energy Conversion Machine of Mechanical Engineering of Malang State University (UM) Indonesia, and Advanced Combustion Lab. Of Mechanical and Aerospace Engineering Faculty of Gyeongsang National University Korea.

\section{References}

1. M. Fiebig, A. Valencia and N. K. Mitra. 7 (1993).

2. Ting Ma, Xing Lu, Jaideep Pandit, Srinath V. Ekkad, Scott T. Huxtable, Applied Energy, 185 (2017).

3. M. Khoshvaght-Aliabadi, Z. Baneshi and S.F. Khaligh. Applied Thermal Engineering, 122 (2017).

4. Samer Ali, Charbel Habchi, Sébastien Menanteau,. Chemical Engineering Science, 162 (2017).

5. M. Khoshvaght-Aliabadi, M.H. Akbari and F.Hormozi. Chinese Journal of Chemical Engineering, 24 (2016).

6. Hao Wu, David S-K. Ting and Steve Ray. Experimental Thermal and Fluid Science, 88 (2017).

7. Li Zhang, Bojun Shang, Huibo Meng, Yaxia Li, Cuihua Wang, Jianhua Wu and Bin Gong. Heat Mass Transfer, 53 (2017).

8. Gautam Biswas, Himadri Chatto padhyay and Anupam Sinha. Heat Transfer Engineering, 33 (2012).

9. Zdanski P.S.B., Pauli D. and Dauner F.A.L.International Communications in Heat and Mass Transfer, 67 (2015).

10. Turo Välikangas, Shobhana Singh and Kim Sørensen. International Journal of Heat and Mass Transfer, 118 (2018).

11. Uddip Kashyap, Koushik Das and Biplab Kumar Debnath. International Journal of Thermal Sciences, 127 (2018).

12. Ghobad Shafiei Sabet, S. Pavithran and R. R. Kulkarni. Iranian Journal of Science and Technology- Transactions of Mechanical Engineering, (2017).

13. Ralph Kristoffer B. Gallegos and Rajnish N. Sharma. Renewable and Sustainable Energy Reviews, 76 (2017).

14. Muhammad Awais and Arafat A. Bhuiyan. Thermal Science and Engineering Progress, 5 (2018).

15. M.J. Li, H. Zhang, J. Zhang, Y.T. Mu, E. Tian, D. Dan, X.D. Zhang and W.Q. Tao. Applied Thermal Engineering, 133 (2018).

16. Suriya Chokphoemphun, Monsak Pimsarn, Chinaruk Thianpong and Pongjet Promvonge. Chinese Journal of Chemical Engineering, 23 (2015).

17. Hao Wu, David S.-K. Ting and Steve Ray. Experimental Thermal and Fluid Science, 94 (2018).

18. Xuehong Wu, DanDan Liu, Min Zhao, YanLi Lu and Xiaoyong Song. Heat Mass Transfer, 52 (2016).

19. Zhiming $\mathrm{Xu}$, Zhimin Han, Jingtao Wang and Zuodong Liu. International Journal of Heat and Mass Transfer, 116 (2018).

20. Hao Wu, David S.-K. Ting and Steve Ray. International Journal of Heat and Mass Transfer, 120 (2018).

21. Joardar A. and Jacobi A. M.International Journal of Refrigeration, 31 (2008).

22. Wu J. M. and Tao W. Q. International Journal of Heat and Mass Transfer, 51 (2008).

23. Hung-Yi Li, Wan-Rong Liao, Tian-Yang Li and Yan-Zuo Chang. International Journal of Heat and Mass Transfer, 112 (2017). 
24. Aris M. S., McGlen R., Owen I. and Sutcliffe C. J. Applied Thermal Engineering, 31 (2011).

25. He Y. L., Chu P., Tao W. Q., Zhang Y. W. and Xie T. Applied Thermal Engineering, 61 (2013).

26. Syaiful, Astrid Ayutasari, Maria F. Soetanto, Ahmad Indra Siswantara and Myung-whan Bae. International Journal of Technology, 8 (2017).

27. Guobing Zhou and Zhizheng Feng. International Journal of Thermal Sciences, 78 (2014). 